\title{
The Mass Line and the Reconstruction of the Legitimacy of the Communist Party of China in the New Era
}

\author{
Hou Wei \\ Marxism Institute, Shenyang Jianzhu University \\ Shenyang, China
}

\begin{abstract}
In order to solve the challenges faced by the Communist Party of China in its original ruling legitimacy, this paper proposes to reinvent the legitimacy of the Chinese Communist Party's ruling legitimacy by insisting on taking the mass line as its focus. In the process of adhering to the mass line, we must combine the tremendous changes that have taken place in the social environment with social development goals. From the aspects of establishing policy response mechanism, strengthening network culture construction, and promoting democratic political construction, we adhere to the mass line in the construction of policy response mechanism, take the mass line in the construction of network culture, and promote the mass line in the construction of democratic politics.
\end{abstract}

Keywords—new era; mass line; governing legitimacy; logical relationship

\section{INTRODUCTION}

Legitimacy is the most basic condition for the ruling party to govern. The ruling party must continue to seek the legitimacy of its ruling status by consolidating its ruling position and realizing the maximum investment of the people with minimal input of administrative capital. The mass line is the lifeline of the party and an important magic weapon for the Chinese Communist Party to defeat the enemy in the practice of the Chinese revolution and China's socialist construction. In the new era, the new party central leadership with Xi Jinping as the core grasps the pulse of the times, regards the people's needs for a better life as the goal of the party, and practices the party's fundamental purpose, that is, firmly grasps the main line of the mass line. Constantly consolidating the party's ruling foundation.

\section{OVERVIEW OF THE MASS LINE AND THE LEGITIMACY OF GOVERNANCE}

\section{A. The connotation and scope of the legitimacy of governance}

"The legitimacy of the ruling is that the public is voluntarily agreeing, supporting and obeying the political order and power system based on the heart" [1]. The legitimacy of governance is based on the recognition of the people by the people and their voluntary acceptance of their leadership. From the perspective of the ruling party, the legitimacy of the ruling party is the authority of the party's ruling party. In the process of ruling, the ruling party can exert its leadership over the people through its own leadership charm and the people's conviction. From the perspective of ordinary people, the legitimacy of governance is the identity, and the people are willing to accept the leadership of the ruling party. In today's era, with peace and development becoming the theme of the times, political democracy and science have gradually become the main theme of a country's politics. The ruling party must exert its authority in the process of ruling, generally based on the voluntary acceptance and conscious obedience of ordinary people. Premise, therefore, the ruling idea and the ruling strategy will affect the ruling party's ruling legitimacy. When the ruling party takes the fundamental interests of the broad masses of the people as the starting point in the ruling process and receives the recognition and support of the broad masses of the people, the ruling party will gain the legitimacy of the ruling party and vice versa.

\section{B. The concept of the mass line and the connotation of the times}

The mass line is the fundamental working line of the Chinese Communist Party and the magic weapon for the party to win the revolution, construction and reform. In different historical periods, due to different historical tasks, the connotation of the mass line also presents a huge difference. In the era of revolutionary war, the first generation of the Party Central Committee represented by Mao Zedong created the mass line and defined its connotation as: "The mass line is the material basis and source of strength of the Chinese revolution", After the founding of New China, with the changes in historical tasks and major social contradictions, the mass line was defined as "the general norm and general mechanism for serving the people, and the basic starting point for the construction of state power and system construction" Since the 19th National Congress of the Communist Party of China, China has entered the stage of decisive victory in building a well-off society in an all-round way. The construction of socialism with Chinese characteristics has also entered a critical period of the new era. Adhere to the "people-centered", "to make people feel, happiness, security, more substantial, more secure, more sustainable" has become the spiritual core of the party's mass line in the new era. 


\section{The Challenges Faced by the Traditional CHINESE COMMUNIST PARTY'S TRADITIONAL GOVERNING LEGITIMATE RESOURCES IN THE NEW ERA}

A. The idea of pluralism has had a huge impact on the mainstream ideology of Marxism

Ideology is a political program. "The concentrated expression of political beliefs and political opinions of any political party requires ideology to provide legitimacy support."[2] Marxist ideology is China's mainstream ideology and the leading idea guiding China's economic and social construction. In the past 40 years of reform and opening up, with the great changes in China's economic society, the content and methods pursued by people's material and spiritual life have undergone tremendous changes. In order to promote the comprehensive and free development of people, the state has created a large free space for people to develop spiritual life. However, China's loose political and social environment has provided a hotbed for the spread of Western capitalist decadent ideas. Some Western capitalist countries use the Internet and other electronic media to continuously export bourgeois ideology such as individualism, money worship, hedonism and other bourgeois ideology to China. This has caused a huge impact on China's mainstream ideology.

B. The legitimacy of governance brought about by the factors of revolutionary achievements has been weakened during the transformation of the main theme of the times

After China entered semi-colonial and semi-feudal society in 1840, striving for national independence and people's liberation became the main historical task of China since modern times. After the founding of the Communist Party of China, in order to obtain the legitimacy of the ruling party, it must have the ability to lead the people in armed struggle against hostile forces and obtain military legitimacy. During the period of the new-democratic revolution, the Chinese Communist Party exerted its ruling position by leading its own revolutionary army to lead the Chinese people to fight for blood and achieve national independence and people's liberation. After the founding of the People's Republic of China, in the process of gradually getting rid of poverty and backwardness in China, the main contradictions of Chinese society and the main theme of the times have undergone tremendous changes. The revolutionary ideas of the past with class struggle as steel have faded from the historical stage. "To become the main theme of the new era, the traditional revolutionary merit factors are gradually weakened during the transformation of the main theme of the times.

\section{The ruling performance brought about by rapid economic growth has gradually dissipated and even went to the opposite}

After the reform and opening up, with the changes in the international and domestic environment, peace and development have become the theme of the times, and promoting economic growth has also become an important strategic measure of the country. After 40 years of reform and opening up, the Chinese economy has achieved world-renowned achievements, which has also enabled the party's governance to gain economic performance. But the economy is only an important part of the social system. When the rapid development of the economy does not drive the overall social progress, even at the expense of other resources of society, the overall social system will eventually be out of balance. In the new era, the main contradictions in China's society and people's interests and demands have undergone tremendous changes. Simply promoting economic growth cannot increase the recognition and support of the broad masses of the people. On the contrary, if economic growth is at the expense of social equity and justice. Simple economic growth will have a negative impact on the legitimacy of governance, and even go to the opposite.

\section{The MASs Line IS THE Logical Starting PoINT FOR THE CHINESE COMMUNIST PARTY TO RESHAPE THE LEGITIMACY OF GOVERNANCE IN THE NEW ERA}

\section{A. Adhere to the "people-centered" work concept can} reconstruct the authority of China's mainstream ideology, so that the party's ruling can obtain legitimacy from the ideological field

General Secretary $\mathrm{Xi}$ Jinping once pointed out that ideological work is an extremely important task of the party. The importance of ideological work lies in the fact that ideology can enable people to identify with the legitimacy of party governance in the field of thought, thus generating strong cohesiveness and centripetal force. Adhering to the "people-centered" work philosophy is to use the Marxist historical materialism as a guide, respect the people's dominant position, and think that the people's interests are the ultimate goal of the party. Adhering to the "people-centered" work philosophy can enable the Chinese Communist Party to gain legitimacy from the ideological field.

\section{B. Adhere to the working methods of "down-to-earth for the} benefit of the people", to deeply explore the needs of contemporary social development, so that the party's governance can obtain legitimacy from the level of compliance with social development

Society has its objective law of operation, not the transfer of human will, and society is a collection of people and people's relationship. People's activities create society, and the people's pursuit of their own interests is to promote the development of society. power. Therefore, in order to comply with the law of social development and to meet the needs of social development, the ruling party must take the interests of the people as the core and work for the people in a down-to-earth manner. The report of the 19th National Congress of the Communist Party of China pointed out that "the initial intention and mission of the Chinese communists is to seek happiness for the Chinese people and seek rejuvenation for the Chinese nation". In the new era, the Chinese communists can only comply with the original laws and principles of social development by keeping their minds and missions in mind, working hard, making welfare for the people, improving the material and cultural living standards of people, and solving the contradictions between inadequate and unbalanced development. Let the party's governance gain legitimacy from the level of compliance with the laws of social operation. 


\section{Adhere to the work style of "the party's flesh-and-blood ties with the masses of the people" can arouse the people's political identity with the party and enable the party's ruling to obtain legitimacy from the level of interest identification}

The ruling party represents the interests of the class. In the process of ruling, the ruling party must take the class as the starting point and the foothold to gain support from the class or the class. The Communist Party of China is the representative of the fundamental interests of the broadest masses of the people. The Communist Party of China can only gain the recognition and support of the broad masses of the people by taking the fundamental interests of the broadest masses of the people as the starting point and the foothold of the party's governance. This requires the Chinese Communist Party members to always keep the people in their hearts, work for the people, and constantly establish a good image to win the trust of the people and maintain the "female connection between the party and the people." When the Communists are unmotivated and always put the interests of the people first, the Chinese Communist Party will gain legitimacy from the level of public interest.

\section{THE COMMUNIST PARTY OF CHINA ADHERES TO THE PATH CHOICE OF THE MASS LINE IN THE NEW ERA}

How to adhere to the mass line in the new era, so that the mass line can be implemented in a real way, and can exert good political and social effects, is the key content that the Communist Party of China should consider as a ruling party in the new era. Combining the new characteristics of China's politics, economy and culture in the new era and the environment of the times in China's current stage, the Communist Party of China adheres to the mass line in the new era and can proceed from the following aspects:

\section{A. Adhere to the mass line in the construction of the policy response mechanism}

Adhering to the party's mass line in the new era is to ensure the party's advanced nature and purity, and to eliminate the problems of corruption and non-action of individual Communist Party members. In view of this, in the process of upholding the mass line, the party should dig deeper into the form, promptly make clear and effective responses to the unhealthy trend of the party, and build a policy response mechanism to ensure that public resources and national policies meet the fundamental needs of the people.

\section{$B$. Take the mass line in the construction of network culture. \\ With the full arrival of the web2.0 era, networked learning, work and life have gradually become the normal mode of people}

With the help of the Internet, we can better publicize the masses and mobilize the masses, and also closely contact the masses and realize the wholeheartedly for the people. In the process of upholding the mass line, the Communist Party of China must keep pace with the times, realize the organic integration of the mass line and modern network technology, give full play to the advantages of "traditional science and technology", and innovate the mode of the mass line.

\section{Promote the mass line in the construction of democratic politics}

The mass line is a useful supplement to the socialist democratic politics with Chinese characteristics and plays an important role in promoting China's democratic political construction. However, from the perspective of the nature and function of the mass line, the mass line is also a supplement to the practical operation level, not the right Sublimation on the theoretical level. In practice, if you do not pay attention to the norms and guidance of the democratic political system, it is easy to produce deviations or even the opposite effect. Therefore, when adhering to the mass line, we must focus on building and improving the democratic political system and using a sound democratic system to guide and standardize the mass line. This is not only the internal requirement of implementing the mass line, but also the basis for the legitimacy of the Communist Party of China in the new era.

\section{CONCLUSION}

The mass line is the fundamental working line of the Chinese Communist Party and an important magic weapon for the Chinese Communist Party to win the revolution, construction and reform. In the new era, China's social environment has undergone tremendous changes, and China's social development goals have also undergone major changes. The original foundation of the Chinese Communist Party's ruling legitimacy faces challenges: the idea of pluralism is the mainstream ideology of Marxism. The ruling legitimacy brought about by the huge impact and revolutionary merit factors has been weakened during the transformation of the main theme of the times, and the ruling performance brought about by rapid economic growth has gradually dissipated and even went to the opposite side. Adhering to the mass line is the logical starting point and important way to reshape the legitimacy of the Communist Party of China in the new era. In the new era, the Communist Party of China adheres to the path of the mass line, including adhering to the mass line in the construction of the policy response mechanism, taking the mass line in the construction of network culture, and advancing the mass line in the construction of democratic politics.

\section{ACKNOWLEDGMENT}

Sources of the project: 1. Liaoning Province Graduate Student Enrollment Quality Project: Research on Graduate Student Enrollment Quality Evaluation and Guarantee Mechanism (YZ2018YB035) 2. Liaoning Social Science Planning Fund Project: University Counselor Performance Evaluation System and Incentive Mechanism Research (L18BSZ013).

\section{About the Author:}

Hou Wei (1980-), female, associate professor of Shenyang Jianzhu University, postdoctoral, master tutor, engaged in ideological and political education research.

Contact: Marxism Institute, Shenyang Jianzhu University, No. 9 Weinan East Road, Hunnan New District, Shenyang, China Postcode: 110168 


\section{REFERENCES}

[1] Zhou Jianchao. The Times Appeal of the CPC's Ruling Legality [J]. Nanjing Social Sciences 2006 (5).

[2] Zhao Zilin. The expansion of the legitimacy resources of the Communist Party of China since the 18th National Congress [J]. Seeking truth from facts 2017 (5). 